\title{
Effect of postpartum depression on exclusive breast-feeding practices in sub- Saharan Africa countries: a systematic review and meta-analysis
}

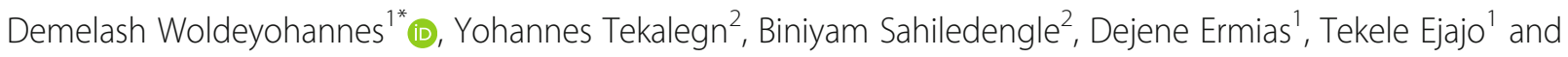
Lillian Mwanri ${ }^{3}$

\begin{abstract}
Background: Postpartum depression (PPD) is a serious mood disorder that affects behavioural, physical and mental health of women and newborn after childbirth. Although a wide range of research have been conducted on maternal and infant health outcomes, the effect of postpartum depression on exclusive breastfeeding practices remains ambiguous, and needs addressing. The aim of this study was to assess the effect of postpartum depression on exclusive breast feeding practices in sub-Saharan African countries.

Methods: PubMed, Google Scholar, Science Direct and Cochrane Library were systematically searched for relevant articles published between 2001 and 2020. STATA version 14 was used to calculate the pooled odd ratio with 95\% confidence intervals $(95 \% \mathrm{Cl})$. The DerSimonian and Laird random effects meta-analysis was used to measure the effect of postpartum depression on exclusive breast feeding practices. The heterogeneity and publication bias were assessed by using $I^{2}$ test statistics and Egger's test, respectively. This review was reported according to the Preferred Reporting Items for Systematic Reviews and Meta-Analysis.

Result: A total of 1482 published articles and gray literatures were retrieved from different databases. Additional articles were identified from the reference list of identified reports and articles. After assessment of obtained articles, studies not meeting the inclusion criteria were excluded. Twenty six studies involving 30,021 population met the inclusion criteria were included in this review. In sub Saharan Africa the overall estimated level of postpartum depression was $18.6 \%$ ( $95 \% \mathrm{Cl}: 13.8,23.4)$. This review found that postpartum depression had no significant effect on exclusive breast feeding practices $(\mathrm{OR}=0.46,95 \% \mathrm{Cl}: 0.18,1.14)$.

Conclusion: In Sub Saharan Africa, the prevalence of postpartum depression was lower than the report of World Health Organization for developing Country in 2020. This review reveled that maternal postpartum depression has no significant effect on exclusive breast feeding practices. Thus, the investigators strongly recommend the researchers to conduct primary studies using strong study design in sub-Saharan Africa.
\end{abstract}

Keywords: Exclusive breast feeding practices, Postpartum depression, Sub-Saharan Africa

* Correspondence: woldemel@wcu.edu.et

${ }^{1}$ Department of Public Health, College of Medicine and Health Science,

Wachemo University, Hossana, Ethiopia

Full list of author information is available at the end of the article

C C The Author(s). 2021 Open Access This article is licensed under a Creative Commons Attribution 4.0 International License, which permits use, sharing, adaptation, distribution and reproduction in any medium or format, as long as you give appropriate credit to the original author(s) and the source, provide a link to the Creative Commons licence, and indicate if changes were made. The images or other third party material in this article are included in the article's Creative Commons licence, unless indicated otherwise in a credit line to the material. If material is not included in the article's Creative Commons licence and your intended use is not permitted by statutory regulation or exceeds the permitted use, you will need to obtain permission directly from the copyright holder. To view a copy of this licence, visit http://creativecommons.org/licenses/by/4.0/. The Creative Commons Public Domain Dedication waiver (http://creativecommons.org/publicdomain/zero/1.0/) applies to the data made available in this article, unless otherwise stated in a credit line to the data. 


\section{Background}

Depression is a serious mood disorder that is estimated to affect the health of 350 million people worldwide. It is a common mental health disorder that is estimated to affect $10-15 \%$ of all mothers in the postpartum period [1-3]. Postpartum depression is a disorder experienced by women following the childbirth and may arise from a combination of hormonal changes, psychological adjustment to motherhood and fatigue [1].

Studies have found that in the first three months after childbirth, $14.5 \%$ of women have an episode of minor or major depression, with nearly $40 \%$ of these women having experienced symptoms during pregnancy $[4,5]$.

Postpartum depression has a considerable burden on partners and close family members, affecting social and leisure activities and posing financial challenges within the family. Additionally, postpartum depression has an adverse effect on the marital relationship [6-8].

There has been significant research in developed countries on the prevalence of postpartum depression and its effect on exclusive breast feeding practices. Meta-analyses of these studies have identified past history of psychopathology, emotional disturbance during pregnancy, difficult marital relationships, inadequate social support and stressful life events as the primary risk factors for developing postnatal depression [7, 9, 10].

Mothers with postpartum depression are more likely to have an unhealthy lifestyle, including poor diet and sleep patterns, compared to mothers free of postnatal depression [11-13]. Women with postnatal depression tend to stop breastfeeding earlier than non-depressed mothers [14-16].

Despite some evidence of a higher risk for depression, most low-income and ethnic minority women remain undiagnosed or untreated for postpartum depression [17]. Postpartum depression is a significant public health concern with wide-ranging negative consequences for women and their children [18-20].

Postpartum depression is associated with impairment of the mother-infant bond, which can result in longer-term disruption of the emotional and cognitive development of the infant [7]. Mothers with postpartum depression are less likely to appropriately interpret and respond to infant signals; have more negative than positive emotions toward their infants and are more likely to intrusive in their interactions with their infants [21]. In comparison, a study conducted in South Africa showed no clear effects of postnatal depression on exclusive breast feeding practices, although postnatal depression at two months was found to be associated with low infant weight at 18 months [22].

A study conducted in Malawi found a significant association of postpartum depression with exclusive breast feeding practices. All of the studies conducted in South Africa, Malawi and Ethiopia identified a high prevalence of postpartum depression (34, 26 and 33\%, respectively) but failed to identify significant effect of postpartum depression on exclusive breast feeding practices [22-24].

In Ethiopia, postpartum depression was not associated with adverse exclusive breast feeding in any aspects [25]. Such conflicting results from primary studies, coupled with the absence of any systematic reviews focused on the prevalence of PPD and its effect on exclusive breast feeding practices in sub-Saharan African countries, indicate the need for clarification of the effects of maternal postnatal depression on exclusive breast feeding practices. A preliminary search for systematic reviews on this topic was performed in PubMed, CINAHL, DARE and PROSPERO and not found existing systematic reviews that reported the effect of postpartum depression on exclusive breast feeding practices in sub-Saharan African countries. This study seeks to systematically review the best available evidence regarding the effect of postnatal depression on exclusive breast feeding practices in subSaharan African countries.

\section{Method}

\section{Search strategy}

A three-step search strategy was used in this review. Firstly, an initial limited search of MEDLINE/PubMed was undertaken, followed by an analysis of the text words contained in the title and abstract and the index terms used to describe the articles. A second search using all identified keywords and index terms was undertaken across databases, including PubMed, Google Scholar, Science Direct, Proquest MedNar and Cochrane Library. Thirdly, the reference list of all identified reports and articles was searched for additional studies.

The initial keywords were postnatal, postpartum, depression, mental disorders and exclusive breast feeding practices. These keywords were used separately and/or in combination using Boolean operators such as "OR" or "AND". "Depression, postpartum"[All fields] AND ("africa south of the sahara"[MeSH Terms] OR and "prevalence" [Subheading] OR "("africa south of the sahara"[MeSH Terms]" [All fields] AND "Ethiopia" [MeSH Terms] OR "africa south of the sahara"[All Fields]), "Infant breastfeeding".

\section{Study selection \\ Inclusion criteria \\ Study setting: Sub-Sahara Africa.}

Study participants: Exclusive Breast feeding mothers.

Publication condition: All published articles and gray literatures.

Language: English language.

Types of studies: Observational study designs.

Publication date: From January 2001 to June 28, 2020, due to the lack of studies from sub Saharan Africa on the topic before 2001. 
Exclusion criteria: Unable to access full-texts after two email contacts of the principal investigator.

\section{Types of exposure}

This review considered studies that examined exclusive breast feeding practices in women with postpartum depression versus women without postpartum depression.

Postpartum depression is defined as depression that starts within one month after childbirth and whose symptoms last more than two weeks. We can measure postnatal depression by using the Diagnostic and Statistical Manual of Mental Disorders or Edinburgh Postnatal Depression Scale and self-reporting questionnaire-20. This review excluded studies that have been conducted on mothers with preexisting psychological disorders.

\section{Outcome of interests}

The outcome interest of this review was the pooled prevalence of PPD and its effect on exclusive breast feeding practices in Sub Saharan Africa. Effect size was estimated in the form of log odds ratios.

\section{Types of studies}

This review considered studies with observational study designs: prospective, retrospective follow up studies and cross-sectional studies reporting an association between postpartum depression and exclusive breast feeding practices were considered for this review.

\section{Methodological quality}

Quality of each original study was assessed independently (DW, YT) by using Newcastle-Ottawa Scale (NOS)

Table 1 Characteristics of studies included in the systematic review and meta-analysis on the effect of postpartum on exclusive breast feeding practices in Sub-Saharan Africa, 2020

\begin{tabular}{|c|c|c|c|c|c|c|c|c|}
\hline Author & Year & Country & Sub regions & Study setting & Study design & Sample size & $\begin{array}{l}\text { Prevalence of } \\
\text { PPD with } \mathrm{Cl}\end{array}$ & $\begin{array}{l}\text { Tool } \\
\text { Used }\end{array}$ \\
\hline Adamu and Adinew [27] & 2018 & Ethiopia & Eastern Africa & Facility Based & Cross-sectional study & 618 & $23.3(19.9,26.6)$ & EPHD \\
\hline Anokye et al. [28] & 2018 & Ghana & Western Africa & Facility Based & Cross-sectional study & 257 & $7(3.9,10.1)$ & PHQ \\
\hline Azale et al. [29] & 2016 & Ethiopia & Eastern Africa & Community Based & Cross-sectional study & 3147 & $11.2(10.1,12.3)$ & PHQ \\
\hline Bitew et al. [30] & 2019 & Ethiopia & Eastern Africa & Facility Based & Prospective study & 1240 & $22.1(19.8,24.4)$ & $\mathrm{PHQ}$ \\
\hline Christodoulou et al. [31] & 2019 & South Africa & Southern Africa & Facility Based & Prospective study & 468 & $15.6(12.3,18.9)$ & EPHD \\
\hline Dow et al. [32] & 2014 & Malawian & Southern Africa & Community Based & Prospective study & 492 & $10.9(8.2,13.7)$ & EPHD \\
\hline Garman et al. [33] & 2019 & South Africa & Southern Africa & Facility Based & Prospective study & 351 & $9.4(6.3,12.5)$ & HDRS \\
\hline Huang et al. [34] & 2018 & Uganda & Eastern Africa & Community Based & Cross-sectional study & 303 & $28.1(22.9,33.1)$ & $\mathrm{PHQ}$ \\
\hline Kerie et al. [35] & 2018 & Ethiopia & Eastern Africa & Facility Based & Cross-sectional study & 408 & $33.8(29.2,38.4)$ & EPHD \\
\hline Khalifa et al. [36] & 2015 & Sudan & Eastern Africa & Facility Based & Cross-sectional study & 236 & $9.3(5.6,13.1)$ & EPHD \\
\hline Khalifa et al. [37] & 2018 & Sudan & Eastern Africa & Facility Based & Cross-sectional study & 223 & $3.6(1.1,6.1)$ & EPHD \\
\hline Madeghe et al. [38] & 2016 & Kenya & Eastern Africa & Facility Based & Cross-sectional study & 200 & $13(8.3,17.7)$ & EPHD \\
\hline Juliet E.M Nakku [39] & 2006 & Uganda & Eastern Africa & Facility Based & Cross-sectional study & 465 & $8.2(5.7,10.7)$ & $\mathrm{SRQ}$ \\
\hline $\begin{array}{l}\text { R. Ndokera and } \\
\text { C. MacArthur [40] }\end{array}$ & 2010 & Zambia & Southern Africa & Facility Based & Cross-sectional study & 278 & $9.7(6.2,13.2)$ & $\mathrm{SRQ}$ \\
\hline Nhiwatiwa [41] & 1998 & Zimbabwe & Southern Africa & Community Based & Prospective study & 500 & $19(15.6,22.4)$ & SSQ \\
\hline Ongeri et al. [42] & 2018 & Kenya & Eastern Africa & Facility Based & Prospective study & 171 & $18.7(12.9,24.6)$ & EPHD \\
\hline Osok et al. [43] & 2018 & Kenya & Eastern Africa & Facility Based & Cross-sectional study & 176 & $32.9(26,39.9)$ & $\mathrm{PHQ}$ \\
\hline P.G. Ramchandani et al. [44] & 2009 & South Africa & Southern Africa & Facility Based & Cross-sectional study & 1035 & $16.4(14.2,18.7)$ & \\
\hline S. Shamu et al. [45] & 2016 & Zimbabwe & Southern Africa & Facility Based & Cross-sectional study & 824 & $21.8(19,24.7)$ & SQR \\
\hline Stellenberg EL, [46] & 2015 & South Africa & Southern Africa & Community Based & Cross-sectional study & 159 & $50.3(42.5,58.1)$ & EPHD \\
\hline Robert C. Stewart [47] & 2010 & Malawi & Western Africa & Facility Based & Cross-sectional study & 501 & $30.5(26.5,34.5)$ & SQR \\
\hline Toru et al. [48] & 2018 & Ethiopia & Eastern Africa & Community Based & Cross-sectional study & 456 & $22.4(18.5,26.2)$ & CES-D \\
\hline Wemakor and Iddrisu [49] & 2018 & Ghana & Western Africa & Community Based & Cross-sectional study & 200 & $33.5(26.9,40)$ & CES-D \\
\hline Weobong et al. [50] & 2015 & Ghana & Western Africa & Facility Based & Prospective study & 13,360 & $3.4(3.1,3.7)$ & SQR \\
\hline Rohde SS [51]. & 2014 & South Africa & Southern Africa & Facility Based & Cross sectional study & 3494 & $15.9(14.8,17.2)$ & EPHD \\
\hline Abdulai, H [52]. & 2019 & Ghana & Western Africa & Facility Based & Cross sectional study & 300 & $27.3(22.3,32.4)$ & $\mathrm{SHQ}$ \\
\hline
\end{tabular}

Note: CES-D Centre for Epidemiologic Studies-Depression, EPHD Edinburgh Postnatal Depression, PHQ Patient Health Questionnaire, SRQ Self-reporting Questionnaire, SSQ Shona Symptom Questionnaire 
quality assessment tool [26]. Any disagreements were resolved by taking the mean score. Finally, studies with a scale of $\geq 5$ out of 10 were considered as achieving high quality. Any disagreements that arise between the reviewers were resolved through discussion with a third reviewer $(\mathrm{BS})$ (Table 1).

\section{Data extraction}

The standard data extraction tool was prepared in a Microsoft Excel spreadsheet. This included the specific details about the exposures, populations, study methods and outcomes of significance to the review question and specific objectives. The authors of primary studies were contacted by email in case there is incomplete information. Two reviewers (DW and YT) extracted the data independently. Any differences among reviewers were negotiated with review team members until agreement was reached.

\section{Data synthesis}

Data were analyzed using STATA version 14. Heterogeneity was assessed using the standard $I^{2}$ and visual inspection of forest plots. To check publication bias, both objective and subjective (funnel plot) methods were used. Mainly, objective methods such as Eggers' and Beggs' tests $(p$-value $<0.05)$ were used to assess publication bias [53, 54]. The result of Eggers' test revealed statistically significant publication bias ( $p$-value $<$ 0.001). Finally, Duval and Tweedie's nonparametric trim and fill analysis was performed to account for this publication bias. The pooled prevalence and effect size was expressed as standardized mean differences and their 95\% confidence intervals were calculated using the DerSimonian and Laird method. Moreover, odds ratios and their $95 \%$ confidence intervals were calculated.

\section{Result}

\section{Characteristics of the studies}

A total of 1482 studies were retrieved from different databases. After removing the duplicate articles $(n=$ 233) and after reading titles and abstracts, 1115 articles were further excluded due not in line with our inclusion criteria. After reading the abstracts, additional 105 articles were excluded. Finally, a total of 33 full text studies were downloaded and assessed their eligibility. Among full text articles, seven articles were excluded because they did not meet inclusion criteria (in four papers outcome of interests was not reported and the three of papers were no a primary study). Finally, 26 articles were used for the meta-analysis. This process has been reported (Fig. 1) according to the preferred

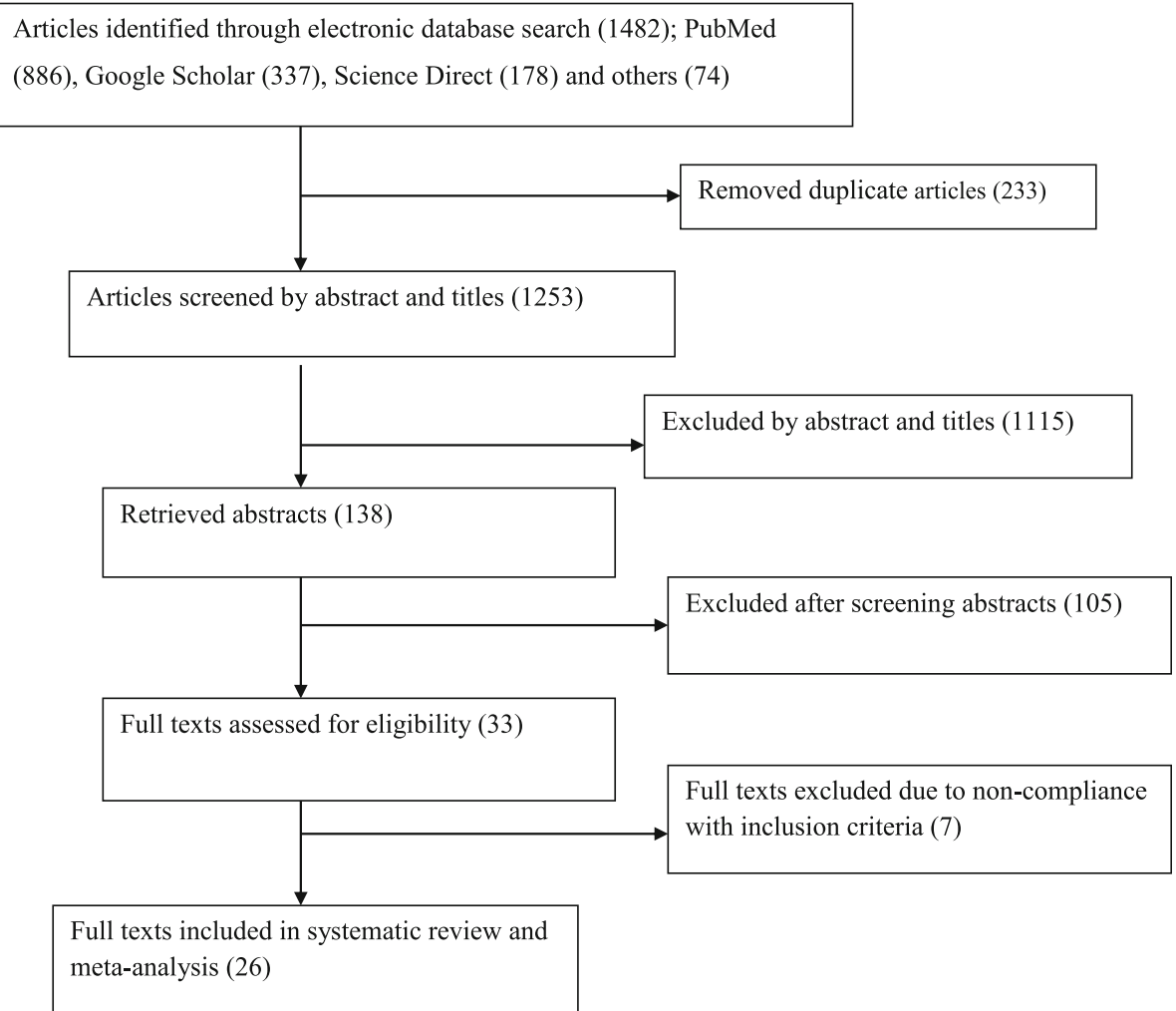

Fig. 1 Flow diagram shows the study selection of the meta-analysis of the effect of postpartum depression on exclusive breast feeding practices in Sub-Saharan Africa, 2020 
Study

ID

Adamu and Adinew (2018)

Anokye et al. (2018)

Azale et al. (2016)

Bitew et al. (2016)

Christodoulou et al. (2020)

Dow et al. (2014)

Garman et al. (2019)

Huang et al. (2018)

Kerie et al. (2018)

Khalifa et al (2015)

Khalifa et al. (2018)

Madeghe et al. (2016)

Juliet E.M Nakku (2006)

R. Ndokera and C. MacArthur (2010)

Nhiwatiwa (1998)

Ongeri et al. (2018)

Osok et al. (2018)

P.G. Ramchandani et al. (2009)

S. Shamu et al. (2016)

Stellenberg EL, (2015)

Robert C. Stewart (2009)

Toru et al. (2018)

Wemakor and Iddrisu (2018)

Weobong et al. (2015)

Rohde SS.(25) (2005)

Hikmatu Abdulai (2019)

Overall (I-squared $=98.8 \%, p=0.000)$

NOTE: Weights are from random effects analysis

$-58.1$
ES $(95 \% \mathrm{Cl})$

$23.30(19.97,26.63)$ $7.00(3.88,10.12)$

$11.22(10.11,12.32)$

$22.10(19.79,24.41)$

$15.60(12.31,18.89)$

$10.98(8.21,13.74)$

$9.40(6.35,12.45)$

$28.05(22.99,33.11)$

$33.82(29.23,38.41)$

$9.32(5.61,13.03)$

$3.59(1.15,6.03)$

$13.00(8.34,17.66)$

$8.17(5.68,10.66)$

$9.71(6.23,13.19)$

$19.00(15.56,22.44)$

$18.71(12.87,24.56)$

$32.95(26.01,39.90)$

$16.43(14.17,18.68)$

$21.84(19.02,24.67)$

$50.31(42.54,58.09)$

$30.54(26.51,34.57)$

$22.37(18.54,26.19)$

$33.50(26.96,40.04)$

$3.41(3.10,3.71)$

$16.00(14.78,17.21)$

$27.33(22.29,32.38)$

$18.79(15.15,22.43)$

Fig. 2 Forest plot displaying the pooled prevalence of postpartum depression in Sub-Saharan Africa, 2020

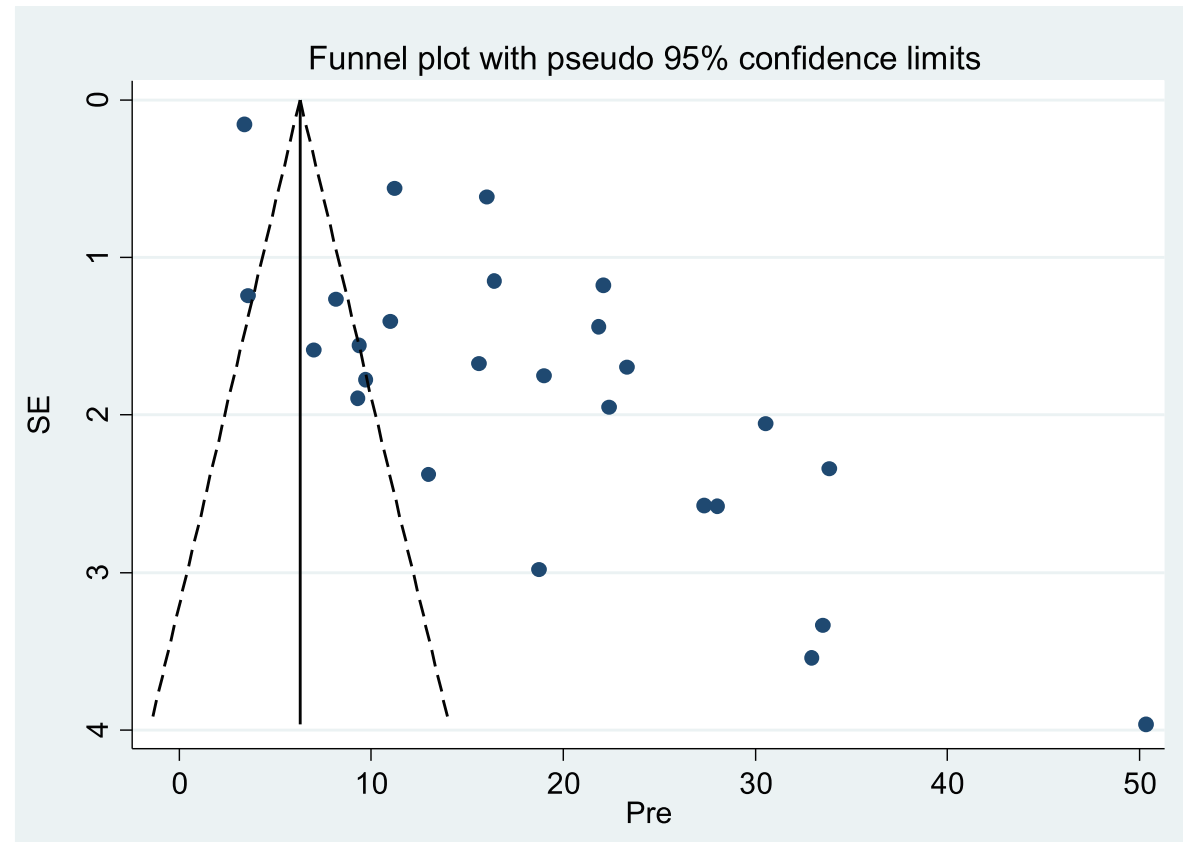

Fig. 3 Funnel plot of pool prevalence of postpartum depression in Sub-Saharan Africa, 2020 
Table 2 Results from the trim-and-fill method for publication bias in 26 studies on effect of postpartum depression on exclusive breast feeding practices in Sub Saharan Africa, 2020

\begin{tabular}{|c|c|c|c|c|c|c|}
\hline \multirow[t]{2}{*}{ Method } & \multirow{2}{*}{$\begin{array}{l}\text { Pooled } \\
\text { Estimate (\%) }\end{array}$} & \multicolumn{2}{|l|}{$95 \% \mathrm{Cl}$} & \multirow[t]{2}{*}{$Z$ value } & \multirow[t]{2}{*}{$p$-values } & \multirow{2}{*}{$\begin{array}{l}\text { Estimated } \\
\text { Number } \\
\text { of studies }\end{array}$} \\
\hline & & Lower & Upper & & & \\
\hline Fixed effect & 6.293 & 6.027 & 6.560 & 46.258 & 0.001 & 26 \\
\hline Random & 18.791 & 15.154 & 22.428 & 10.125 & 0.001 & \\
\hline
\end{tabular}

reporting items for systematic reviews and metaanalyses [55]. Of the included articles: 19 were crosssectional study designs [27-29, 34-40, 43-49, 51, 52] and seven studies were a prospective cohort studies [30-33, 41, 42, 50] and they comprised a population of 30,021 . The minimum sample size from the included study was 159 [46] from South Africa, whereas the maximum sample size from the included study was 13,360; from Ghana [50]. The prevalence of postpartum depression in Sub-Saharan Africa ranged from $3.4 \%$ in Kintampo Health Research Centre in Ghana [50] to $50.3 \%$ in rural South Africa [46]. The summary of characteristics of included studies is reported in Table 1 below.

\section{Pooled prevalence of postpartum depression}

Overall random effects estimate of the postpartum depression across Sub Saharan Africa studies was 18.79\% (95\% CI: 15.15, 22.43\%) (Fig. 2). This observed effect size varies somewhat from study to study. Test statistics results showed high heterogeneity $\left(I^{2}=98.8 \%, p<0.001\right)$ and Eggers' test ( $p$-value <0.001) revealed significant publication bias. The possible publication biases were visualized thru funnel plots. Symmetrical large inverted funnels resembled the presence of publication biases (Fig. 3). After we applied trim and fill meta-analysis, the overall random effect estimates of postpartum depression across studies was $18.92 \%$ (95\% CI: 15.1, 22.7\%) Table 2. The prevalence of postpartum depression vary in sub regions of Sub Saharan Africa, which was 20.2\% (95\% CI: 7.7, 32.6) in western Africa, 18.6\% (95\% CI: 13.8, 23.4) in Eastern Africa and 18.3\% (95\% CI: 13.4, 23.3) in southern Africa (Table 3).

\section{Effects of postpartum depression on exclusive breast feeding practices}

This systematic review and meta-analysis assessed the effect of postpartum depression on exclusive breast feeding practices. Four studies assessed the effect of effect of postpartum depression on the exclusive breast feeding practices. Heterogeneity was moderate across studies $\left(\mathrm{I}^{2}=75.1 \%, p=0.007\right)$, which enabled us to use a random effects model. Using this method, our meta-analysis found that postpartum depression had no significant effect on exclusive breast feeding practices $(\mathrm{OR}=0.46,95 \% \mathrm{CI}$ : 0.18, 1.14) (Fig. 4). We explored possible sources of heterogeneity using Univariate meta-regression using publication year and sample size as covariates. However, none of these variables were statistically significant for explaining heterogeneity (Table 4). The presence of publication bias was also assessed using funnel plots and Eggers' and Beggs' statistical tests at the 5\% significance level. The funnel plot shows a symmetrical distribution (Fig. 5). Egger and Beggs' tests showed no significant publication bias with $p$-values of 0.642 and 0.734 , respectively. The influence of a single study on the overall meta-analysis estimate was assessed by sensitivity analysis using a random effects model and revealed that no single study influenced the overall effect of postpartum depression on exclusive breast feeding practices.

\section{Discussion}

By 2020, the World Health Organization projected that depression will become the second and significant predictor of the global burden of disease [56]. One in five women in low- and middle-income countries developed postpartum depression according to reviews conducted in Low and Middle Income Countries (LMICS) and a review conducted in Africa [57, 58]. Evidence has shown that common mental disorders, including depression, during the postpartum period are more prevalent compared with non-pregnancy periods [59].

A study conducted in Malawi found the effect of postpartum depression on exclusive breast feeding practices.

Table 3 Subgroup level of postpartum depression by sub regions of Sub Saharan Africa, 2020

\begin{tabular}{lllll}
\hline Variable & Characteristics & Included studies & Sample size & Estimated prevalence of PPD (95\% Cl) \\
\hline Sub region & Eastern Africa & 12 & 7643 & $18.6(13.8,23.4)$ \\
& Western Africa & 5 & 14,618 & $20.2(7.7,32.6)$ \\
& Southern Africa & 9 & 7601 & $17.7(14.0,21.5)$ \\
\hline
\end{tabular}




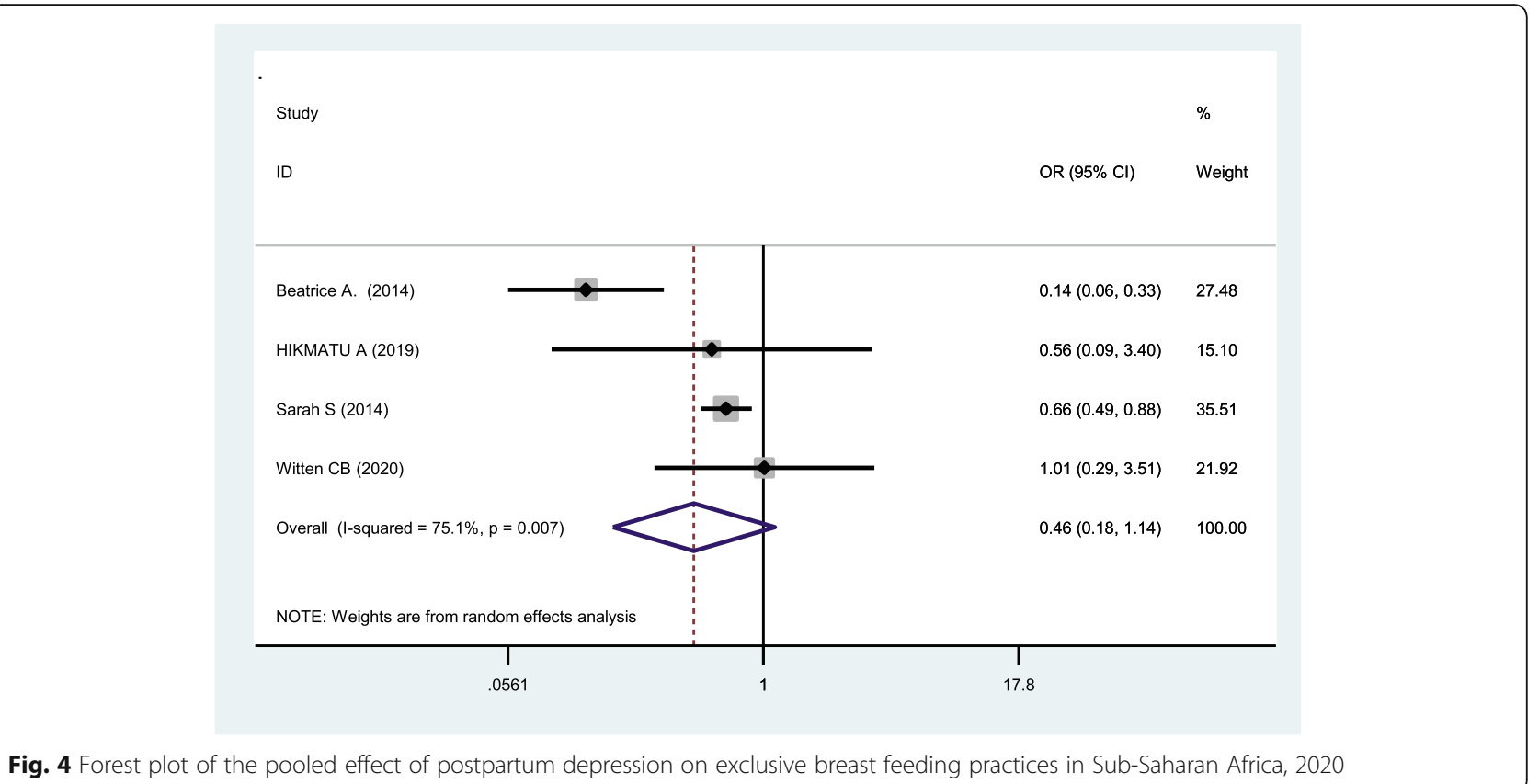

Fig. 4 Forest plot of the pooled effect of postpartum depression on exclusive breast feeding practices in Sub-Saharan Africa, 2020

All of the studies conducted in South Africa, Malawi and Ethiopia identified a high prevalence of postpartum depression (34, 26 and 33\%, respectively) but failed to identify the effect of postpartum depression on exclusive breast feeding practices $[24,25,60]$. Whereas, in this review the prevalence of postpartum depression in Sub Saharan Africa was $18.9 \%$ this finding was higher than a review conducted in Africa [61]. The prevalence of postpartum depression varies in sub regions of Sub Saharan Africa, which was 20.2\% in western Africa, $18.6 \%$ in Eastern Africa and $18.3 \%$ in southern Africa. This showed that there is conflicting result seen for the prevalence of postpartum depression and its effect on exclusive breast feeding practices [18, 19]. Hence, this systematic review and meta-analysis is perhaps the first of its kind to be conducted in Sub-Saharan Africa to examine the effect of postpartum depression on exclusive breast feeding practices.

This systematic review and meta-analysis revealed that postpartum depression has no significant effect on exclusive breast feeding practices. This finding is

Table 4 Related factors with heterogeneity of the effects of postpartum depression on exclusive breast feeding practices in Sub-Saharan Africa, 2020

\begin{tabular}{lll}
\hline Variable & Coefficients & $\boldsymbol{P}$-value \\
\hline Year & 0.2650735 & 0.533 \\
Sample size & -0.0013525 & 0.103 \\
\hline
\end{tabular}

in agreement with individual studies conducted in the Republic of Korea [62], South Africa [60], Malawi [24], Ethiopia [25], Malaysia [63], Brazil [64], and Saudi Arabia [36], whereas the finding of this study was in contrast to a qualitative systematic review [65], a study conducted in Saudi Arabia [66] and a study conducted in Mexico [66]. These disagreements could be the result of sociodemographic and socioeconomic differences between the countries. The other potential explanations for the observed differences might be the use of different tools to assess postpartum depression. The difference in sample size and different study periods may be the additional causes for these variations. In the above studies, the results were based on individual studies, but this systematic review and meta-analysis pooled the effect of postpartum depression on exclusive breast feeding practices based on the four studies conducted in different study areas and periods. However, a study conducted in Canada showed that the effect of postpartum depression on infant feeding depends on the duration of exclusive breast feeding [15].

\section{Limitations of the study}

Maximum efforts have been made to include all published articles and gray literatures from sub-Saharan African countries. Moreover, $97 \%$ of the studies in this meta-analysis were cross-sectional study design. Chicken egg relationships, therefore, cannot be shown in this review. 


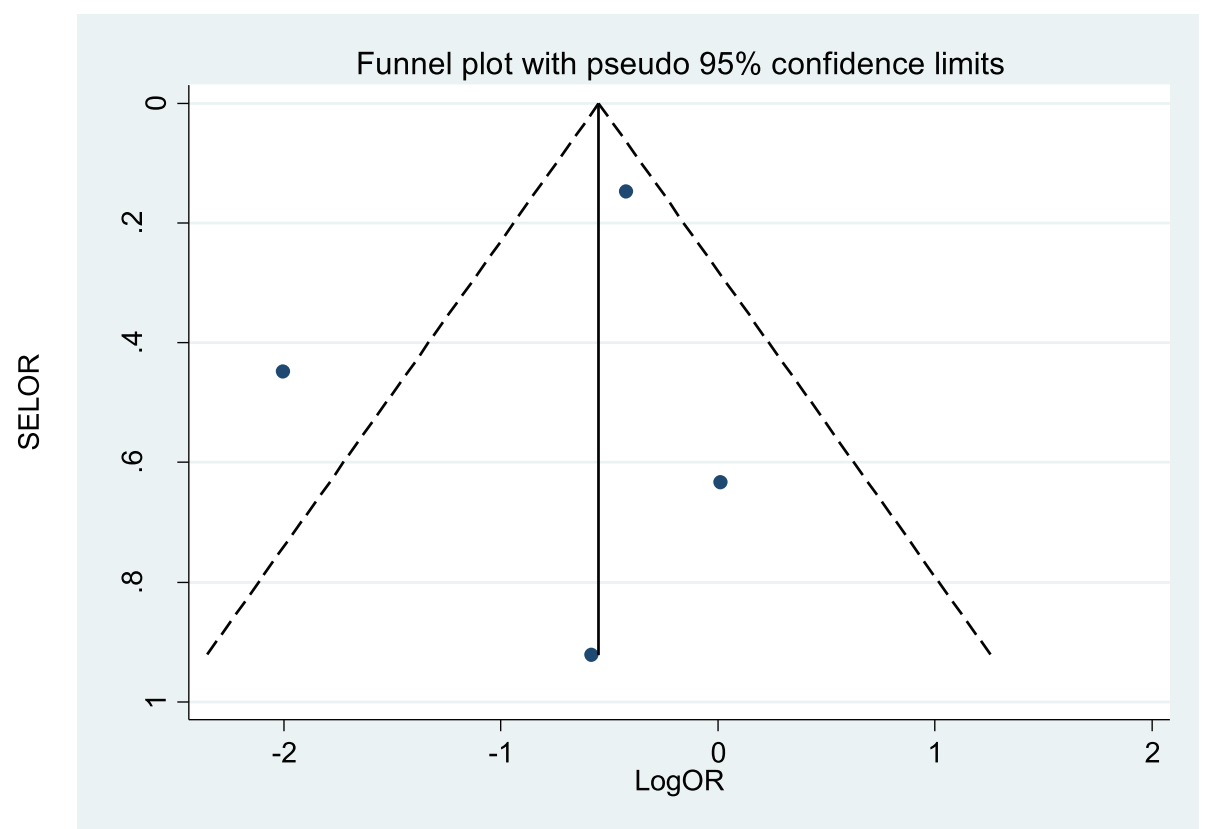

Fig. 5 Funnel plot of the effect of postpartum depression on exclusive breast feeding practices in Sub-Saharan Africa, 2020

\section{Conclusions}

In Sub Saharan Africa, the prevalence of postpartum depression was lower than the report of WHO for developing Country in 2020. This review revealed that maternal postpartum depression has no significant effect on exclusive breast feeding practices. Thus, the investigators strongly recommend the researchers to conduct primary studies with strong study design that can rule out the effect of PPD on breast feeding practices in sub-Saharan Africa.

\section{Abbreviations}

AOR: Adjusted odds ratio; PPD: Postpartum depression; PRISMA: preferred reporting items for systematic reviews and meta-analyses

\section{Acknowledgements}

We would like to acknowledge all Librarians for their cooperation.

\section{Authors' contributions}

DW: Conception of the research protocol, study design, literature review, data extraction, data analysis, interpretation and drafting of the manuscript; DW \& YT: quality assessment, and BS, YT, LM, DE and TE reviewed the manuscript. All authors have read and approved the manuscript.

\section{Funding}

Not applicable.

\section{Availability of data and materials}

This study was based on a literature review of published studies in SubSaharan Africa. Anyone who needs to access the data can contact the author concerning the studies included in the analysis. The reference list can also be used to directly access the articles.

\section{Ethics approval and consent to participate}

Not applicable

\section{Consent for publication}

Not applicable.

\section{Competing interests}

The authors declare that they have no competing interests.

\section{Author details}

'Department of Public Health, College of Medicine and Health Science, Wachemo University, Hossana, Ethiopia. ${ }^{2}$ Department of Public Health, College Health Science, Madda Walabu University, Bale Robe, Ethiopia. ${ }^{3}$ College of Medicine and Public Health, Flinders University, Health Sciences Building, Sturt Road, Bedford Park, Adelaide, SA 5001, Australia.

Received: 24 September 2020 Accepted: 29 December 2020 Published online: 08 February 2021

\section{References}

1. Abdollahi F, Lye M-S, Zain AM, Ghazali SS, Zarghami M. Postnatal depression and its associated factors in women from different cultures. Iran J Psychiatr Behav Sci. 2011:5(2):5.

2. Gavin NI, Gaynes BN, Lohr KN, Meltzer-Brody S, Gartlehner G, Swinson T. Perinatal depression: a systematic review of prevalence and incidence. Obstet Gynecol. 2005;106(5):1071-83.

3. O'hara MW, Swain AM. Rates and risk of postpartum depression-a metaanalysis. Int Rev Psychiatr. 1996;8(1):37-54.

4. Gaynes BN, Gavin N, Meltzer-Brody S, Lohr KN, Swinson T, Gartlehner G, et al. Perinatal depression: prevalence, screening accuracy, and screening outcomes. Evid Rep/Technol Assess (Summary). 2005;(119):1-8.

5. Surkan PJ, Kennedy CE, Hurley KM, Black MM. Maternal depression and early childhood growth in developing countries: systematic review and metaanalysis. Bull World Health Organ. 2011;89:607-15.

6. Boath E, Pryce A, Cox J. Postnatal depression: the impact on the family. J Reprod Infant Psychol. 1998;16(2-3):199-203.

7. Cornish AM, McMahon CA, Ungerer JA, Barnett B, Kowalenko N, Tennant C. Maternal depression and the experience of parenting in the second postnatal year. J Reprod Infant Psychol. 2006;24(02):121-32.

8. Wilkinson RB, Mulcahy R. Attachment and interpersonal relationships in postnatal depression. J Reprod Infant Psychol. 2010;28(3):252-65.

9. Beck CT. Predictors of postpartum depression: an update. Nurs Res. 2001; 50(5):275-85.

10. Dadi AF, Miller ER, Mwanri L. Postnatal depression and its association with adverse infant health outcomes in low-and middle-income countries: a systematic review and meta-analysis. BMC Pregnancy Child. 2020;20(1):1-15. 
11. Christensen L, Somers S. Adequacy of the dietary intake of depressed individuals. J Am Coll Nutr. 1994;13(6):597-600.

12. George GC, Milani TJ, Hanss-Nuss H, Freeland-Graves JH. Compliance with dietary guidelines and relationship to psychosocial factors in low-income women in late postpartum. J Am Diet Assoc. 2005;105(6):916-26.

13. Paulson JF, Dauber S, Leiferman JA. Individual and combined effects of postpartum depression in mothers and fathers on parenting behavior. Pediatrics. 2006;118(2):659-68.

14. Adewuya AO, Ola BO, Aloba OO, Mapayi BM, Okeniyi JA. Impact of postnatal depression on infants' growth in Nigeria. J Affect Disord. 2008; 108(1-2):191-3.

15. Dennis $\mathrm{CL}$, McQueen K. Does maternal postpartum depressive symptomatology influence infant feeding outcomes? Acta Paediatr. 2007; 96(4):590-4.

16. McLearn KT, Minkovitz CS, Strobino DM, Marks E, Hou W. Maternal depressive symptoms at 2 to 4 months post partum and early parenting practices. Arch Pediatr Adolesc Med. 2006;160(3):279-84.

17. Husain N, Bevc I, Husain M, Chaudhry I, Atif N, Rahman A. Prevalence and social correlates of postnatal depression in a low income country. Arch Women's Mental Health. 2006;9(4):197-202.

18. Goodman SH, Gotlib $H$. Children of depressed parents: mechanisms of risk and implications for treatment. Washington, DC. 2002.

19. Grace SL, Evindar A, Stewart D. The effect of postpartum depression on child cognitive development and behavior: a review and critical analysis of the literature. Arch Women's Mental Health. 2003;6(4):263-74.

20. Dadi AF, Mwanri L, Woodman RJ, Azale T, Miller ER. Causal mechanisms of postnatal depression among women in Gondar town, Ethiopia: application of a stress-process model with generalized structural equation modeling. Reprod Health. 2020;17:1-15.

21. Boyd RC, Zayas LH, McKee MD. Mother-infant interaction, life events and prenatal and postpartum depressive symptoms among urban minority women in primary care. Matern Child Health J. 2006:10(2):139.

22. Tomlinson M, Cooper $P$, Murray $L$. The mother-infant relationship and infant attachment in a south African peri-urban settlement. Child Dev. 2005; 76(5):1044-54

23. Harpham T, Huttly S, De Silva MJ, Abramsky T. Maternal mental health and child nutritional status in four developing countries. J Epidemiol Community Health. 2005:59(12):1060-4.

24. Stewart RC, Umar E, Kauye F, Bunn J, Vokhiwa M, Fitzgerald M, et al. Maternal common mental disorder and infant growth-a cross-sectional study from Malawi. Matern Child Nutr. 2008;4(3):209-19.

25. Servili C, Medhin G, Hanlon C, Tomlinson M, Worku B, Baheretibeb Y, et al. Maternal common mental disorders and infant development in Ethiopia: the P-MaMiE birth cohort. BMC Public Health. 2010;10(1):693.

26. Xue D, Qian C, Yang L, Wang X. Risk factors for surgical site infections afte breast surgery: a systematic review and meta-analysis. Eur J Surg Oncol (EJSO). 2012;38(5):375-81.

27. Adamu AF, Adinew YM. Domestic violence as a risk factor for postpartum depression among Ethiopian women: facility based study. Clin Pract Epidemiol Mental Health. 2018;14:109.

28. Anokye R, Acheampong E, Budu-Ainooson A, Obeng El, Akwasi AG. Prevalence of postpartum depression and interventions utilized for its management. Ann General Psychiatry. 2018;17(1):18.

29. Azale T, Fekadu A, Hanlon C. Treatment gap and help-seeking for postpartum depression in a rural African setting. BMC Psychiatry. 2016;16(1):196.

30. Bitew T, Hanlon C, Medhin G, Fekadu A. Antenatal predictors of incident and persistent postnatal depressive symptoms in rural Ethiopia: a population-based prospective study. Reprod Health. 2019;16.

31. Christodoulou J, Le Roux K, Tomlinson M, Le Roux IM, Katzen LS, RotheramBorus MJ. Perinatal maternal depression in rural South Africa: child outcomes over the first two years. J Affect Disord. 2019;247:168-74.

32. Dow A, Dube Q, Pence BW, Van Rie A. Postpartum Depression and HIV Infection among Women in Malawi. J Acquired Immune Def Synd (1999). 2014:65(3):359-65.

33. Garman EC, Schneider M, Lund C. Perinatal depressive symptoms among low-income south African women at risk of depression: trajectories and predictors. BMC Pregnancy Child. 2019;19.

34. Huang KY, Abura G, Theise R, Nakigudde J. Parental depression and associations with parenting and Children's physical and mental health in a sub-Saharan African setting. Child Psychiatry Hum Dev. 2017:48(4): 517-27.
35. Kerie S, Menberu M, Niguse W. Prevalence and associated factors of postpartum depression in southwest, Ethiopia, 2017: a cross-sectional study. BMC Res Notes. 2018:11.

36. Khalifa DS, Glavin K, Bjertness E, Lien L. Postnatal depression among Sudanese women: prevalence and validation of the Edinburgh postnatal depression scale at 3 months postpartum. Int J Women's Health. 2015;7:677.

37. Khalifa DS, Glavin K, Bjertness E, Lien L. Course of depression symptoms between 3 and 8 months after delivery using two screening tools (EPDS and HSCL-10) on a sample of Sudanese women in Khartoum state. BMC Pregnancy Child. 2018:18.

38. Madeghe BA, Kimani VN, Vander Stoep A, Nicodimos S, Kumar M Postpartum depression and infant feeding practices in a low income urban settlement in Nairobi-Kenya. BMC Res Notes. 2016;9.

39. Nakku JE, Nakasi G, Mirembe F. Postpartum major depression at six weeks in primary health care: prevalence and associated factors. Afr Health Sci. 2006; 6(4):207-14

40. Ndokera $\mathrm{R}$, MacArthur $\mathrm{C}$. The relationship between maternal depression and adverse infant health outcomes in Zambia: a cross-sectional feasibility study. Child Care Health Dev. 2011:37(1):74-81.

41. Nhiwatiwa S, Patel V, Acuda W. Predicting postnatal mental disorder with a screening questionnaire: a prospective cohort study from Zimbabwe. J Epidemiol Community Health. 1998;52(4):262-6.

42. Ongeri L, Wanga V, Otieno P, Mbui J, Juma E, Stoep AV, et al. Demographic, psychosocial and clinical factors associated with postpartum depression in Kenyan women. BMC Psychiatry. 2018;18.

43. Osok J, Kigamwa P, Stoep AV, Huang KY, Kumar M. Depression and its psychosocial risk factors in pregnant Kenyan adolescents: a cross-sectional study in a community health Centre of Nairobi. BMC Psychiatry. 2018;18(1): 1.

44. Ramchandani PG, Richter LM, Stein A, Norris SA. Predictors of postnatal depression in an urban south African cohort. J Affect Disord. 2009; 113(3):279-84.

45. Shamu S, Zarowsky C, Roelens K, Temmerman M, Abrahams N. Highfrequency intimate partner violence during pregnancy, postnatal depression and suicidal tendencies in Harare, Zimbabwe. Gen Hosp Psychiatry. 2016;38: 109-14.

46. Stellenberg EL, Abrahams JM. Prevalence of and factors influencing postnatal depression in a rural community in South Africa. Afr J Prim Health Care Fam Med. 2015;7(1)

47. Stewart RC, Bunn J, Vokhiwa M, Umar E, Kauye F, Fitzgerald M, et al. Common mental disorder and associated factors amongst women with young infants in rural Malawi. Soc Psychiatry Psychiatr Epidemiol. 2010;45(5): $551-9$.

48. Toru T, Chemir F, Anand S. Magnitude of postpartum depression and associated factors among women in Mizan Aman town, bench Maji zone, Southwest Ethiopia. BMC Pregnancy Child. 2018;18.

49. Wemakor A, Iddrisu H. Maternal depression does not affect complementary feeding indicators or stunting status of young children (6-23 months) in northern Ghana. BMC Res Notes. 2018;11(1):408

50. Weobong B, Ten Asbroek AH, Soremekun S, Danso S, Owusu-Agyei S, Prince $M$, et al. Determinants of postnatal depression in rural Ghana: findings from the Don population based cohort study. Depress Anxiety. 2015:32(2):108-19.

51. Rohde SS. Exploring the association between postnatal depressed mood and infant morbidity, growth, and feeding at 12 weeks postpartum in a peri-urban south African setting: University of Cape Town; 2014.

52. Abdulai H. Postpartum depression, breastfeeding practices and nutritional status of children at two health facilities in Accra. Ghana: University of Ghana; 2019.

53. Egger M, Smith GD, Schneider M, Minder C. Bias in meta-analysis detected by a simple, graphical test. BMJ. 1997;315(7109):629-34.

54. Begg CB, Mazumdar M. Operating characteristics of a rank correlation test for publication bias. Biometrics. 1994:1088-101.

55. Moher DA, Liberati J, Tetzlaff DG, Altman P. Grp, preferred reporting items for systematic reviews and meta-analyses: the PRISMA statement (reprinted from annals of internal medicine). Phys Ther. 2009;89:873-80.

56. UNAIDs U, Organization WH. Global HIV/AIDS response: epidemic update and health sector progress towards universal access: progress report 2011 Global HIV/AIDS response: epidemic update and health sector progress towards universal access: progress report 2011. 2011. 
57. Fisher J, MCd M, Patel V, Rahman A, Tran T, Holton S, et al. prevalence and determinants of common perinatal mental disorders in women in low-and lower-middle-income countries: a systematic review. Bull World Health Organ. 2012;90:139-49.

58. Hong TT, Dat TTH, Hoa NP, Cuong PV, Cuc NTK. Expression of a novel gene encoding protease inhibitor from metagenome of sponge in Vietnam. Acad JBiol. 2018;40(4):77-84.

59. Sawyer A, Ayers S, Smith H. Pre-and postnatal psychological wellbeing in Africa: a systematic review. J Affect Disord. 2010;123(1-3):17-29.

60. Witten C, Claasen N, Kruger HS, Coutsoudis A, Grobler H. Psychosocial barriers and enablers of exclusive breastfeeding: lived experiences of mothers in low-income townships, North West Province. South Africa Int Breastfeed J. 2020;15(1):1-5.

61. Dadi AF, Akalu TY, Baraki AG, Wolde HF. Epidemiology of postnatal depression and its associated factors in Africa: a systematic review and meta-analysis. PLoS One. 2020;15(4):e0231940.

62. Lee E, Bae S, Park M. Relationship between postpartum depression and breastfeeding adaptation among lactating mothers. Int J Bio-Sci BioTechnol. 2016;8(3):183-92.

63. Mohamad Yusuff AS. Breastfeeding and postnatal depression in Sabah. Malaysia: Curtin University; 2013.

64. Hasselmann MH, Werneck GL, CVCd S. Symptoms of postpartum depression and early interruption of exclusive breastfeeding in the first two months of life. Cadernos Saude Publica. 2008;24:s341-s52.

65. Dennis C-L, McQueen K. The relationship between infant-feeding outcomes and postpartum depression: a qualitative systematic review. Pediatrics. 2009. 123(4):e736-e51

66. Flores-Quijano ME, Córdova A, Contreras-Ramírez V, Farias-Hernández L, Cruz Tolentino M, Casanueva E. Risk for postpartum depression, breastfeeding practices, and mammary gland permeability. J Hum Lact. 2008;24(1):50-7.

\section{Publisher's Note}

Springer Nature remains neutral with regard to jurisdictional claims in published maps and institutional affiliations.

Ready to submit your research? Choose BMC and benefit from:

- fast, convenient online submission

- thorough peer review by experienced researchers in your field

- rapid publication on acceptance

- support for research data, including large and complex data types

- gold Open Access which fosters wider collaboration and increased citations

- maximum visibility for your research: over $100 \mathrm{M}$ website views per year

At $\mathrm{BMC}$, research is always in progress.

Learn more biomedcentral.com/submissions 